\author{
Artem Artyukhov and Vsevolod Sklabinskyi
}

\title{
HYDRODYNAMICS OF GAS FLOW IN SMALL-SIZED VORTEX GRAN ULATORS IN THE PRODUCTION OF NITROGEN FERTILIZERS
}

\author{
Sumy State University \\ 2, Rimsky-Korsakov str., 40007 Sumy, Ukraine; artyukhov@ pohnp.sumdu.edu.ua
}

Received: December 02, 2013/ Revised: February 11, 2014 / Accepted: September 02, 2014

(C) Artyukhov A., Sklabinskyi V., 2015

\begin{abstract}
This paper presents the prospective line of studying such chemical process as granulation and the advantages of small universal vortex granulators usage in chemical processes, for example, for the production of nitrogen mineral fertilizers, complex mineral fertilizers and porous ammonium nitrate (PAN). The mathematical calculations for determining the hydrodynamic characteristics of gas flow movement, which ultimately affect the crystallization process in the workspace of the vortex granulator, are described. Components of a gas flow velocity and the granulator design impact on them are analytically determined. A comparison of theoretical and experimental studies is given.
\end{abstract}

Keywords: vortex granulator, nitrogen mineral fertilizers, porous ammonium nitrate gas flow, hydrodynamics, velocity.

\section{Introduction}

Granulation is the final stage in the complex of the working operations in mineral fertilizers production. The quality of the marketable product, economic and environmental characteristics of the production depend on the efficiency of this process.

At present, methods of granulation in drum apparatus (phosphate fertilizers - superphosphate, ammophos) and granulation towers (nitrogen fertilizers - ammonium nitrate $\mathrm{NH}_{4} \mathrm{NO}_{3}$, carbamide $\left.\mathrm{CO}\left(\mathrm{NH}_{2}\right)_{2}\right)$ are widely adopted in the production of mineral fertilizers. Granulation towers are also used for PAN production. Most of them have currently completed their operative life and need to be replaced by more modern, efficient and economical equipment.

Granulation process in these types of equipment is characterized by a number of drawbacks: their large size, low specific productivity, significant energy output and the need for powerful dust collecting apparatus for outgoing gases.

Due to the rapid development of such industries like $\mathrm{NH}_{4} \mathrm{NO}_{3}$ and $\mathrm{CO}\left(\mathrm{NH}_{2}\right)_{2}$, ammonium sulfate, NPK fertilizer (NPK), powdered detergents, etc. in Ukraine and abroad these shortcomings should be eliminated in design of new granulation plants and at modernization of the existing ones.

Granulation towers, which were built in 60-70s of the last century on the territory of Ukraine (most of them for production of $\mathrm{NH}_{4} \mathrm{NO}_{3}$, namely units AC-60, AC-67, AC-72) have physically exhausted their resources and started to break down. Application of granulation towers in PAN production requires additional costs for melting down modifying and cellulating elements.

Methods of granulation $\mathrm{NH}_{4} \mathrm{NO}_{3}$ and $\mathrm{CO}\left(\mathrm{NH}_{2}\right)_{2}$ in a fluid bed have not yet received wide industrial application and are used much less frequently than granulation by melt spraying. The main obstacle in the way of their development is the formation of a large number of small droplets when spraying melt into a fluid bed; the upward flow of rarefied air carries away a part of these droplets from the layer in the form of hardened small particles.

A retrieval of new ways of production of granulated products in chemical technology for obtaining fertilizers and porous ammonium nitrate (PAN) indicates a move to increasing the use of the capacity of the working equipment and its power density. This can be achieved by improving the equipment design and new ways of organizing flows of continuous and dispersed phases.

One of the methods of reducing the size of granulation equipment in chemical technology is to increase the relative velocity of the continuous and dispersed phases [1]. This can be achieved through the use of the vortex and highly turbulized flows in the fluid bed 
apparatus [2]. Performance improvement (load in phase) for devices with such flows movement organization leads to a smaller relative increase in their dimensions and energy consumption for graining.

Nowadays, fluid bed vortex apparatus of national [3-5] and foreign manufacturers (Urea Casale SA, Kahl Group, Neuhaus Neotec, Changzhou Xianfeng Drying Equipment Company Ltd and others) are applied in granular products technology.

In the apparatus of this type, rotary flow of heat carrier ensures the well-ordered movement of the material. Because of the suspended circular motion, the material does not form agglomerates.

Along with the advantages that characterize the current designs of the devices (reduced size, creation of intensive hydrodynamics in the working volume) there are some flaws that adversely affect the quality of the granulated product:

- inability to control the residence time of the dispersed phase in a unit volume;

- creation of dead zones in the lower part of the device;

- reduction of monodispersity degree of the granulated product due to the lack of classification process.

These drawbacks are eliminated by the application of universal vortex granulators that combine the processes of granulation, classification, drying and cooling in the working volume [6, 7] (Fig. 1). Devices of this type, due to rapid reset, can be used in the manufacture of granular products in the chemical, food, pharmaceutical, mining and other industries. In this paper, vortex granulators are considered as an example of using the new highperformance equipment for the production of ordinary and porous ammonium nitrate in chemical technology.

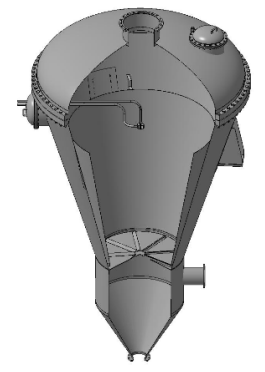

a)

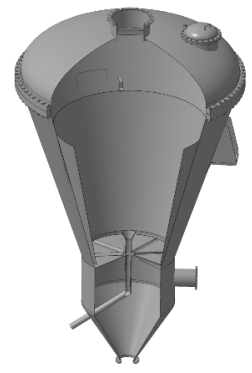

b)

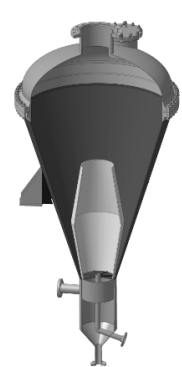

c)
Fig. 1. Vortex granulator designs: spraying the melt (a); with a previous wetting of granules and simple inner case (b) and with a previous wetting of granules and composite inner case (c)
For the successful implementation of the granulation process in such vortex apparatus it is required to study the hydrodynamic conditions of the flows' motion in their working volume. The hydrodynamics of the workspace of the vortex granulator has a decisive influence on the residence time of granules in the case of the device and on its height. Definition of the optimum hydrodynamic environment of the vortex apparatus allows to create the equipment with minimum dimensions that provide the minimum residence time of the drops (granules) in the device and finished product classification. This approach is particularly relevant and is in keeping with today's emphasis on energy efficiency in the design.

This paper is a continuation of the series of the research works on hydrodynamics of the single-phase (gas) vortex flow in small granulators designed for granulated mineral fertilizers and PAN production. The purpose of the work is to research the field of gas flow rates based on the analytical solution of mathematical model equations. The object of the study is the vortex granulators for obtaining a granulated ordinary and porous ammonium nitrate. The subject of the study is hydrodynamic characteristics of the swirling gas flow in the vortex granulators with variable cross-sectional area.

\section{Theoretical Bases of the Gas Flows Motion in the Working Volume of the Vortex Granulator}

When calculating hydrodynamic parameters for vortex flows the methods that are based on the equations of an ideal or viscous fluid motion and (or) experimental data are used [8].
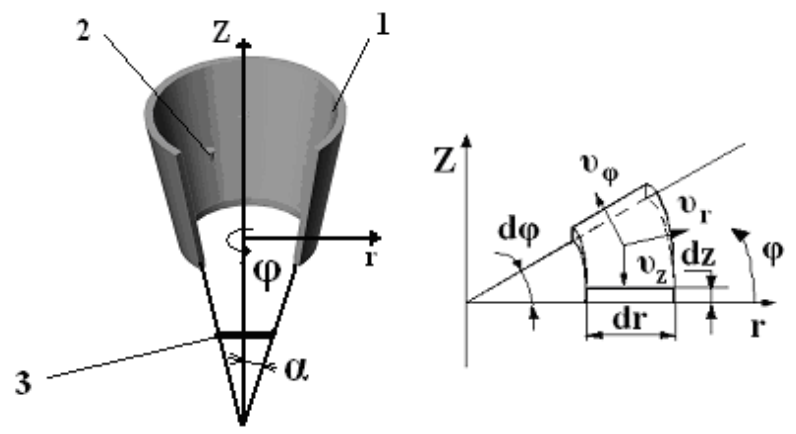

Fig. 2. Scheme of the elementary volume of the gas in the cylindrical coordinate system $(r, \varphi, z)$ : a workspace of the granulator (1); elementary volume of the gas (2) and gas distribution unit; $d r, d \varphi, d z$ - elementary growth for the corresponding coordinate axes $(3) ; V_{r}, V_{\varphi}, V_{Z}$ - radial,

circumferential and axial (longitudinal) components of the gas rate, respectively; $\alpha$ - half opening angle of the diffuser 
To solve the Navier-Stokes equation concerning a particular problem of the vortex motion of the gas flow in the variable workspace cross-sectional area, it is necessary to apply a rational coordinate system for possible simplifications in solving the mathematical model equations. The best option of coordinate system to choose is a cylindrical coordinate system (Fig. 2) [9].

Let's write the Navier-Stokes equation for the motion of the real gas flow in the diffuser (Fig. 2), complementing it with flow continuity equations [9]:

$$
\left.\begin{array}{c}
\mathrm{H}_{\mathrm{V}_{\mathrm{r}}}-\frac{\mathrm{V}_{\varphi}^{2}}{\mathrm{r}}=\mathrm{F}_{\mathrm{r}}-\frac{1}{\rho} \frac{\partial \mathrm{p}}{\partial \mathrm{r}}+\mathrm{E}\left(\Delta v_{\mathrm{r}}-\frac{\mathrm{V}_{\mathrm{r}}}{\mathrm{r}^{2}}-\frac{2}{\mathrm{r}^{2}} \frac{\partial \mathrm{V}_{\varphi}}{\partial \varphi}\right), \\
\mathrm{H}_{\mathrm{V}_{\varphi}}+\frac{\mathrm{V}_{\mathrm{r}} \mathrm{V}_{\varphi}}{\mathrm{r}}=\mathrm{F}_{\varphi}+\mathrm{E}\left(\Delta \mathrm{V}_{\varphi}-\frac{\mathrm{V}_{\varphi}}{\mathrm{r}^{2}}+\frac{2}{\left.\mathrm{r}^{2} \frac{\partial \mathrm{V}_{\mathrm{r}}}{\partial \varphi}\right),}\right. \\
\mathrm{H}_{\mathrm{V}_{\mathrm{Z}}}=\mathrm{F}_{\mathrm{Z}}-\frac{1}{\rho} \frac{\partial \mathrm{p}}{\partial \mathrm{z}}+\mathrm{E} \Delta \mathrm{V}_{\mathrm{Z}}, \\
\frac{\partial \mathrm{V}_{\mathrm{r}}}{\partial \mathrm{r}}+\frac{1}{\mathrm{r}} \frac{\partial \mathrm{V}_{\varphi}}{\partial \varphi}+\frac{\partial \mathrm{V}_{\mathrm{Z}}}{\partial \mathrm{z}}+\frac{\mathrm{V}_{\mathrm{r}}}{\mathrm{r}}=0
\end{array}\right\}
$$

where $E$ - a coefficient of turbulent viscosity according to the Boussinesq hypothesis [10]; $\mathrm{H}, \Delta$ - differential operators, calculated by dependencies [11]:

$$
\begin{gathered}
\mathrm{H}=\frac{\partial}{\partial \mathrm{t}}+\mathrm{V}_{\mathrm{r}} \frac{\partial}{\partial \mathrm{r}}+\frac{\mathrm{V}_{\varphi}}{\mathrm{r}} \frac{\partial}{\partial \varphi}+\mathrm{V}_{\mathrm{z}} \frac{\partial}{\partial \mathrm{z}} \\
\Delta=\frac{\partial^{2}}{\partial \mathrm{r}^{2}}+\frac{1}{\mathrm{r}} \frac{\partial}{\partial \mathrm{r}}+\frac{1}{\mathrm{r}^{2}} \frac{\partial^{2}}{\partial \varphi^{2}}+\frac{\partial^{2}}{\partial \mathrm{z}^{2}}
\end{gathered}
$$

The main simplification obtained on the basis of theoretical and experimental scientific articles and accepted for solving the problem [12]: the nature of the gas flow is axisymmetrical $\left(\frac{\partial}{\partial \varphi}=0\right)$; the gas flow in the apparatus is taken as the established one $\left(\frac{\partial V_{r}}{\partial \tau}=0\right.$; $\left.\frac{\partial V_{\varphi}}{\partial \tau}=0 ; \frac{\partial V_{z}}{\partial \tau}=0\right)$; the action of the mass forces in case of the elementary volume of the considered gas flow movement can be neglected $\left(\sum \mathrm{F}_{r}=0 ; \quad \sum \mathrm{F}_{\varphi}=0\right.$; $\left.\sum F_{Z}=0\right)$ [9]; the laws of variation of velocity expenditure component and pressure along certain axes of coordinates are given for the particular case.

Based on the above adopted assumptions and simplifications the system of equations (1) and the continuity equation (2) at substitution of expressions (3) and (4) take the form, which takes into consideration $V_{z}$ decrease along $z$-axis

$$
\begin{aligned}
& \mathrm{v}_{\mathrm{r}} \frac{\partial \mathrm{v}_{\mathrm{r}}}{\partial \mathrm{r}}+\mathrm{v}_{\mathrm{z}} \frac{\partial \mathrm{v}_{\mathrm{r}}}{\partial \mathrm{z}}-\frac{\mathrm{v}_{\varphi}^{2}}{\mathrm{r}}= \\
& =-\frac{1}{\rho} \frac{\partial p}{\partial r}+E\left(\frac{\partial^{2} v_{r}}{\partial r^{2}}+\frac{\partial^{2} v_{r}}{\partial z^{2}}+\frac{1}{r} \frac{\partial v_{r}}{\partial r}-\frac{v_{r}}{r^{2}}\right) \\
& \mathrm{V}_{\mathrm{r}} \frac{\partial \mathrm{V}_{\varphi}}{\partial \mathrm{r}}+\mathrm{V}_{\mathrm{z}} \frac{\partial \mathrm{V}_{\varphi}}{\partial \mathrm{z}}-\frac{\mathrm{V}_{\mathrm{r}} \mathrm{V}_{\varphi}}{\mathrm{r}}= \\
& =E\left(\frac{\partial^{2} V_{\varphi}}{\partial r^{2}}+\frac{\partial^{2} V_{\varphi}}{\partial z^{2}}+\frac{1}{r} \frac{\partial V_{\varphi}}{\partial r}-\frac{v_{\varphi}}{r^{2}}\right) \text {, } \\
& \mathrm{V}_{\mathrm{r}} \frac{\partial \mathrm{V}_{\mathbf{z}}}{\partial \mathrm{r}}+\mathrm{V}_{\mathrm{z}} \frac{\partial \mathrm{V}_{\mathbf{z}}}{\partial \mathrm{z}}= \\
& =-\frac{1}{\rho} \frac{\partial \mathrm{p}}{\partial \mathrm{z}}+\mathrm{E}\left(\frac{\partial^{2} \mathrm{v}_{\mathrm{z}}}{\partial \mathrm{r}^{2}}+\frac{1}{\mathrm{r}} \frac{\partial \mathrm{v}_{\mathrm{z}}}{\partial \mathrm{r}}\right) \text {. } \\
& \frac{\partial V_{r}}{\partial r}+\frac{\partial V_{z}}{\partial z}+\frac{V_{r}}{r}=0
\end{aligned}
$$

For a stationary flow in a pipe of a circular cross section the gas flow remains constant for the current radius $r$

$$
Q=2 \pi \int_{0}^{r} r V_{z} d r
$$

From the assumption with regard to the constancy of the longitudinal component of the velocity along the height at the cross-sectional area of the device $S=\pi R^{2}$, whereas for conical workspace of the vortex granulator under the conditions of $r \in[0 ; R]$ the dependence of the solid wall radius from the height has the form of $R=f(z)=\operatorname{tg} \alpha \cdot z$, we write (7) as:

$$
V_{z}(z)=\frac{Q}{\pi R^{2}}=\frac{Q}{\pi \cdot \operatorname{tg} \alpha^{2} \cdot z^{2}}
$$

The analysis and the Eq. (8) show a decrease in a longitudinal component of the gas flow rate throughout the height of the unit due to the increased cross-sectional area of the workspace with the height while maintaining permanency of the gas flow.

Derivative (8) in accordance with $z$ :

$$
\frac{\partial}{\partial z}\left(\frac{Q}{\pi \cdot \operatorname{tg} \varphi^{2} \cdot z^{2}}\right)=-2 \frac{Q}{\pi \cdot \operatorname{tg} \alpha^{2} \cdot z^{3}}
$$

Then the Eq. (2) takes the form:

$$
\left(\frac{\partial}{\partial r} V_{r}(z, r)\right)+\frac{2 \cdot Q}{\pi \cdot \operatorname{tg} \alpha^{2} \cdot z^{3}}+\frac{V r(z, r)}{r}=0
$$


We solve (10) for $V_{r}$ :

$$
V_{r}(z, r)=\frac{-\frac{Q \cdot r^{2}}{\pi \cdot \operatorname{tg}^{2} \cdot z^{3}}+F_{1}(z)}{r} .
$$

where the value $F_{1}(z)=\frac{Q}{z \cdot \pi}$ is determined by the initial conditions $V_{r}(z, r)=0$ at $R=\operatorname{tg} \alpha \cdot z$.

Hence

$$
V_{r 1}(z, r)=\frac{-\frac{Q \cdot r^{2}}{\pi \cdot \operatorname{tg} \alpha^{2} \cdot z^{3}}+\frac{Q}{z \cdot \pi}}{r}
$$

We assume that within a radius of the granulator the circumferential velocity varies according to a quadratic dependence, and along its axis - a linear dependence. The assumption about the change in the circumferential velocity is based on the results of the axisymmetrical vortex flow studies $[9,10]$. Furthermore, at $r=0$ and $z=0$ value $V \varphi=0$, i.e., free term of the general equation of the second degree is 0 .

We solve in the form:

$$
V_{\varphi}(z, r)=A r^{2}+B z r+C r+F z
$$

To solve the equation of the system (5) we require the expressions

$$
\left.\begin{array}{l}
\frac{\partial}{\partial r}\left(A r^{2}+B z r+C r+F z\right)=2 A r+B z+C, \\
\frac{\partial^{2}}{\partial r^{2}}\left(A r^{2}+B z r+C r+F z\right)=2 A, \\
\frac{\partial^{2}}{\partial z^{2}}\left(A r^{2}+B z r+C r+F z\right)=0 .
\end{array}\right\}
$$

form

Then the first equation of the system (5) takes the

$$
\begin{aligned}
& \frac{\left(-\frac{Q \cdot r^{2}}{\pi \cdot \operatorname{tg} \alpha^{2} \cdot z^{3}}+\frac{Q}{z \cdot \pi}\right) \cdot(2 A r+B z+C)}{r}-\frac{2 \cdot Q^{2}}{\pi^{2} \cdot \operatorname{tg} \alpha^{4} \cdot z^{5}}+ \\
& +\frac{\left(-\frac{Q \cdot r^{2}}{\pi \cdot \operatorname{tg} \alpha^{2} \cdot z^{3}}+\frac{Q}{z \cdot \pi}\right) \cdot\left(A r^{2}+B z r+C r+F z\right)}{r^{2}}= \\
& =E\left(2 A+\frac{2 A r+B z+C}{r}-\frac{A r^{2}+B z r+C r+F z}{r^{2}}\right),
\end{aligned}
$$

Values of the coefficients $A, B, C$ and $F$ are obtained considering the following boundary conditions: on the wall of the cone $V \varphi=0$; at half radius of the swirl $V_{\varphi}=V_{\varphi 1}$; in the center of the cone $V \varphi=0$.
We obtain a system of equations:

$$
\left.\begin{array}{l}
\frac{\left(-\frac{Q \cdot r^{2}}{\pi \cdot \operatorname{tg} \alpha^{2} \cdot z^{3}}+\frac{Q}{z \cdot \pi}\right) \cdot(2 A r+B z+C)}{r}-\frac{2 \cdot Q^{2}}{\pi^{2} \cdot \operatorname{tg} \alpha^{4} \cdot z^{5}} \\
+\frac{\left(-\frac{Q \cdot r^{2}}{\pi \cdot \operatorname{tg} \alpha^{2} \cdot z^{3}}+\frac{Q}{z \cdot \pi}\right) \cdot\left(A r^{2}+B z r+C r+F z\right)}{r^{2}}- \\
E\left(2 A+\frac{2 A r+B z+C}{r}-\frac{A r^{2}+B z r+C r+F z}{r^{2}}\right)=0, \\
A z^{2} \cdot \operatorname{tg} \alpha^{2}+B z^{2} \cdot \operatorname{tg} \alpha+C z \cdot \operatorname{tg} \alpha+F z=0, \\
F z=0 ; \\
V_{\varphi 1}=\frac{1}{4} A_{1} z^{2} \cdot \operatorname{tg} \alpha^{2}+\frac{1}{2} B_{1} z^{2} \cdot \operatorname{tg} \alpha+\frac{1}{2} C_{1} z \cdot \operatorname{tg} \alpha+F_{1} z .
\end{array}\right\}
$$

A solution of the system (16) gives the unknown coefficients $A, B, C$ and $F$. After their substitution according to the Eq. (13) a circumferential velocity is defined as $V_{\varphi}(z, r)=f\left(z, r, \alpha, Q, V_{\varphi 1}\right)$ (the form of this solution is bulky and is not given in this paper).

\section{Results and Discussion}

A numerical solution of the equations of the mathematical model allowed us to obtain the basic graphic dependences of gas flow hydrodynamic characteristics in a small conical vortex apparatus with a variable cross section along the height that demonstrates the influence of the workspace geometry and the process parameters on the solid phase velocity fields. An analysis of these graphic dependencies is given below.

The longitudinal component of the gas flow velocity remains constant in the current section of the vortex granulator and decreases monotonically as the height of the working chamber increases (Figs. 3 and 4) due to the law of the change in the value of its section in accordance with the denominator of the Eq. (8). A deceleration of the radial component of the gas flow rate along the radius of the device occurs as approaching the maximum radius of the device workspace at a given height (Figs. 5 and 6).

The circumferential velocity component of the gas flow along the radius of the device has an extremum (maximum) with a gradual decrease in the maximum value when approaching the upper section of the workspace of the machine (Figs. 7-9).

The graphical dependency analysis demonstrates the reduction of the growth zone of circumferential velocity component of the gas flow when increasing its flow rate and narrowing the range of the maximum velocity, a peak velocity remaining constant at the locus in the vortex granulator workspace. 


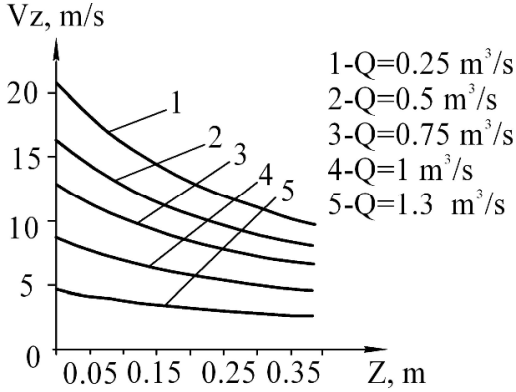

Fig. 3. The calculated change of the longitudinal velocity of the gas flow throughout the height depending on the gas flow rate $\left(\right.$ at $\alpha=13^{\circ}$ )

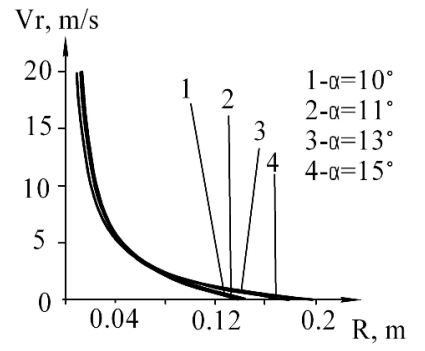

Fig. 6. The calculated change of the radial velocity of the gas flow depending on the opening angle of the cone

(at $Q=0.63 \mathrm{~m}^{3} / \mathrm{s}, z=0.8 \mathrm{~m}$ )

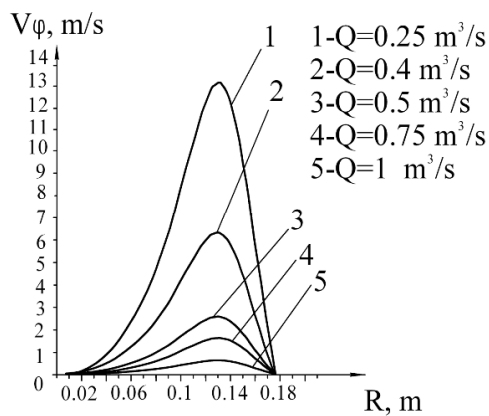

Fig. 8. The calculated change of the circumferential velocity of the gas flow depending on the gas flow rate (at $\alpha=13^{\circ}, z=0.8 \mathrm{~m}$ )

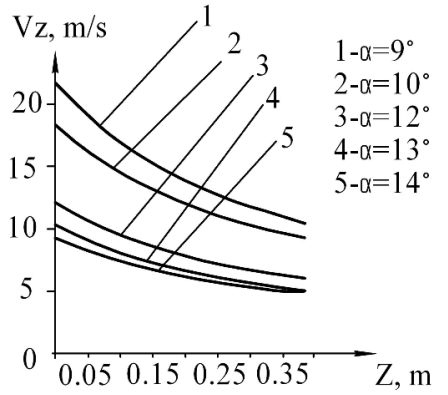

Fig. 4. The calculated change of the longitudinal velocity of the gas flow throughout the height depending on the opening angle of the cone of the vortex granulator workspace (at $Q=0.63 \mathrm{~m}^{3} / \mathrm{s}$ )

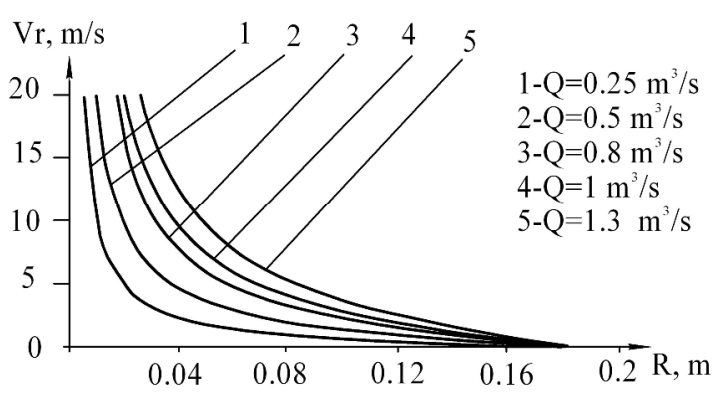

Fig. 5. The calculated change of the radial velocity of the gas flow depending on the gas flow rate (at $\alpha=13^{\circ}, z=0.8 \mathrm{~m}$ )

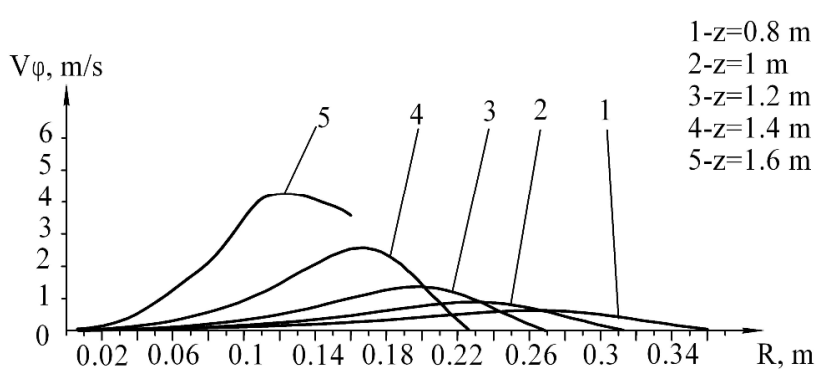

Fig. 7. The calculated change of the circumferential velocity of the gas flow depending on the workspace height of the vortex granulator (at $\alpha=13^{\circ}, Q=0.63 \mathrm{~m}^{3} / \mathrm{s}$ ) at different heights of the device

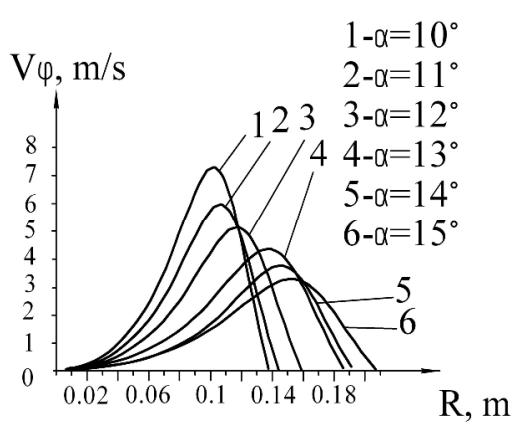

Fig. 9. The calculated change of the circumferential velocity of the gas flow depending on the opening angle of the cone (with $Q=0.63 \mathrm{~m}^{3} / \mathrm{s}, z=0.8 \mathrm{~m}$ )

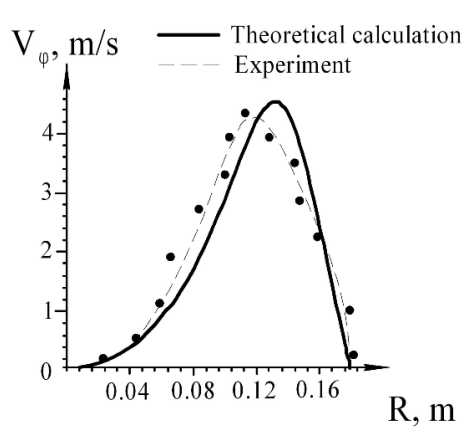

Fig. 10. The comparison of the theoretical and experimental data of the circumferential velocity of the gas flow (at $Q=0.63 \mathrm{~m}^{3} \mathrm{~s}, \alpha=13^{\circ}, z=0.8 \mathrm{~m}$ )
The value of the circumferential velocity with a growing gas flow rate increases more rapidly. At the same time, as the rate of the gas flow in the workspace of the vortex granulator increases, the zone of the slow growth of the circumferential velocity enlarges. Thus, the vortex moves towards the solid wall and becomes more intensive.
The longitudinal and radial velocity components of the gas flow under some initial conditions and at changing geometric and process conditions do not cause a significant change in the quantitative values of the distribution along the radius and the height as for the circumferential velocity component of the gas flow. 
The analysis of Fig. 10 shows the peak of circumferential velocity of the gas flow, obtained experimentally, which is slightly shifted compared with the theoretical calculation. A comparison of theoretical calculations and experimental studies for different sections of the workspace and various corners of the cone opening shows that the zone of maximum circumferential velocity for the arbitrarily chosen section $r$ is $r=0.66-0.72 R$.

The value of the radial velocity of the gas flow, resulted from the analytical solution and experimental data, has a high degree of compliance (Fig. 11). We observe a mutual deviation of the numerical value of the velocity, and, as a whole, a graphic diagram of the radial component of the gas flow full rate has the same character. We observe a uniform decrease of the radial velocity from the center (nucleus) of the gas flow toward its periphery.

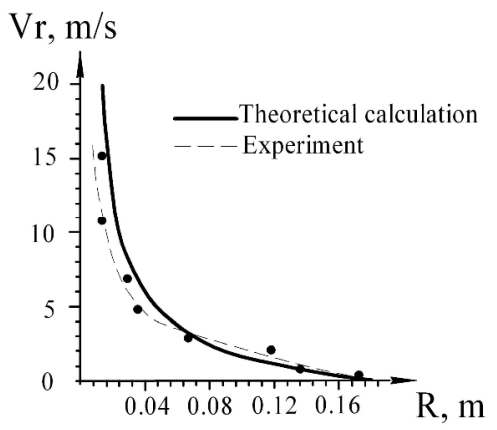

Fig. 11. The comparison of the theoretical and experimental data of the radial velocity of the gas flow (at $Q=0.63 \mathrm{~m}^{3} / \mathrm{s}$, $\left.\alpha=13^{\circ}, z=0.8 \mathrm{~m}\right)$

According to the equations of the mathematical model the basic hydrodynamic characteristics of the gas flow motion in small vortex devices with variable working chamber cross-section are determined.

Data matching of theoretical calculations and experimental studies of hydrodynamics motion of the gas flow in the vortex granulator $[13,14]$ vortex contact trays for gas cleaning in production of nature gas and $\mathrm{NH}_{4} \mathrm{NO}_{3}$ [15] and fluidized bed of granules in the vortex granulator [16] gives satisfactory results. A determination of the measurement error and the results of the basic hydrodynamic characteristics calculation of the interacting flows in the working area of the of the vortex granulator experimental sample are based on the conventional techniques and recommendations for the engineering experiment and the data processing. The error between theoretical and experimental data is up to $10 \%$, which is acceptable for the calculation [17].

\section{Conclusions}

Based on the analysis of the hydrodynamic characteristics of the gas flow as a function of the set of variables, a rational selection of the workspace geometry of the vortex granulator (cone opening angle and height) and a device for swirling a gas flow (angle of the blades of the swirler and their number) becomes possible. These results are the basis of the granule motion hydrodynamic characteristics, the trajectories of its movement and the retention time in the workspace of the vortex granulator. The presented mathematical calculations are also useful for upgrading the existing granulation towers and fluid bed apparatus in production of $\mathrm{NH}_{4} \mathrm{NO}_{3}$ and $\mathrm{CO}\left(\mathrm{NH}_{2}\right)_{2}$, for calculations of similar processes of chemical technology and allow to analyze possible results of the application of high-performance compact vortex granulation equipment more deeply and accurately.

\section{References}

[1] Artyukhov A. and Sklabinskyi V.: Sb. Nauchn. Trudov XX Mezhd. Nauchn-Techn. Conf. Belarus, Minsk 2008, 272.

[2] Artyukhov A., Liaposhchenko O. and Sklabinskyi V.: Visnyk Sumskogo Derg. Univ., 2009, 4, 14.

[3] Klassen P.: Osnovnye Processy Technologii Mineralnykh Udobreniy. Khimiya, Moskwa 1990.

[4] Sazhin B., Lukachesky B., Polevich A. et al.: Pat. USSR 4167541/31-26, Publ. Apr. 7, 1990.

[5] Donat Ye. and Yukhimenko M.: Pat. UA 10288, Publ. Dec. 25, 1996. [6] Artyukhov A. and Sklabinskyi V.: Pat. UA 82754, Publ. May 25, 2008.

[7] Artyukhov A. and Sklabinskyi V.: Pat. UA 99023, Publ. July 10, 2012. [8] Uspensky V.: Doct. thesis, Moscow Inst. Chem. Eng., Moscow 1978.

[9] Shchukin V.: Teploobmen i Hydromechanika Vnutrennykh Potokov v Polyakh Massovykh Sil. Mashinostroenie, Moskwa 1980. [10] Gol'dshtik M.: Vihrevye Potoki. Nauka, Novosibirsk 1981.

[11] Prandtl L. Hydroaeromechanika. NIC RHN, Izhevsk 2000.

[12] Artyukhov A.: $22^{\text {th }}$ Conf. Krain SND "Dispersnye Systemy". Ukraine, Odessa 2006, 40.

[13] Artyukhov A., Marenok V. and Sklabinskyi V.: Visnyk Sumskogo Nats. Agrar. Univ., 2008, 19, 182.

[14] Artyukhov A. and Sklabinskiy V.: Nauk. Visnyk Nats. Hirnychoho Univ., 2013, 6, 42.

[15] Artyukhov A.: Chem. Petrol. Eng., 2014, 49, 736.

[16] Artyukhov A. and Sklabinskyi V.: Chem. \& Chem. Techn., 2015, 2, 175 .

[17] Boyko N. and Ustymenko T.: Theoria i Metody Inzhenernogo Experimenta. Donetsk Nats. Techn. Univ., Donetsk 2009.

\section{ГІДРОДИНАМІКА ГАЗОВОГО ПОТОКУ У МАЛОГАБАРИТНИХ ВИХРОВИХ ГРАНУЛЯТОРАХ ВИРОБНИЦТВА МІНЕРАЛЬНИХ ДОБРИВ}

Анотація. Показано перспективний напрям одного $з$ процесів хімічної технології, яким є гранулювання, та основні переваги використання у хімічних технологіях малогабаритних універсальних вихрових грануляторів, наприклад, для виробництва азотних мінеральних добрив, комплексних мінеральних добрив та пористої аміачної селітри (ПАС). Наведено математичний опис для визначення гідродинамічних характеристик руху газового потоку, які у кінцевому результаті впливають на кристалізаційні процеси, у робочому просторі вихрового гранулятора. Аналітично визначено складові повної швидкості руху газового потоку та вплив на них конструкиії гранулятора. Проведено співставлення результатів теоретичних та експериментальних досліджень.

Ключові слова: вихровий гранулятор, азотні мінеральні добрива, пориста аміачна селітра, газовий потік, гідродинаміка, ивидкість. 